\title{
Clinical Availability of Tumour Biopsy Using Diagnostic Laparoscopy for Advanced Ovarian Cancer
}

\author{
SUGURU ODAJIMA ${ }^{1}$, KAZU UEDA $^{1,2}$, SATOSHI HOSOYA ${ }^{1}$, KEISUKE TOMITA $^{1}$, \\ SAYAKO KATO $^{1}$, YUICHI SHOBURU ${ }^{1,2}$, AYAKO KAWABATA ${ }^{1}$, YASUSHI IIDA ${ }^{1}$, \\ NOZOMU YANAIHARA ${ }^{1}$ and AIKOU OKAMOTO ${ }^{1}$ \\ ${ }^{1}$ Department of Obstetrics and Gynecology, The Jikei University School of Medicine, Tokyo, Japan; \\ ${ }^{2}$ Department of Gynecology, International University of Health and Welfare, Mita Hospital, Tokyo, Japan
}

\begin{abstract}
Background/Aim: Tumour biopsy using laparoscopy before neoadjuvant chemotherapy for advanced ovarian cancer has been widely accepted. However, there are few reports about its operative outcome compared to biopsy with laparotomy. We investigated the advantage of laparoscopic biopsy for advanced ovarian cancer. Patients and Methods: We included 23 patients who underwent laparoscopy and 27 who underwent exploratory laparotomy before neoadjuvant chemotherapy between January 2012 and August 2020. We reviewed their medical records and evaluated their operative outcomes. Results: Blood loss was significantly lower in the laparoscopy group $(5 \mathrm{ml} v \mathrm{vs} .320 \mathrm{ml}$, $p<0.05)$. The period until the initiation of neoadjuvant chemotherapy was significantly shorter in the laparoscopy group (12 days vs. 16 days, $p<0.05)$. Overall survival did not differ significantly between the two groups (25.4 months vs. 24.7 months, $p=0.53)$. Conclusion: Laparoscopic tumour biopsy is useful and safe for histological diagnosis, thereby allowing for early introduction to neoadjuvant chemotherapy.
\end{abstract}

Epithelial ovarian cancer (EOC) is the gynaecological malignancy with the highest mortality rate. At the time of diagnosis, most patients have stage III or IV disease classified according to the International Federation of Gynecology and Obstetrics (FIGO) staging system, indicating that the tumour has disseminated into the peritoneal cavity and/or

This article is freely accessible online.

Correspondence to: Kazu Ueda, Department of Gynecology, International University of Health and Welfare, Mita Hospital, 1-4-3 Mita, Minato-ku, Tokyo, Japan. Tel: +81 334518121, Fax: +81 34540067, e-mail: kazu@iuhw.ac.jp

Key Words: Advanced ovarian cancer, diagnostic laparoscopy, interval debulking surgery, laparoscopic surgery, tumour biopsy. metastasized to organs outside the pelvis. Adequate surgical cytoreduction is the most important independent prognostic factor, and the standard treatment for advanced EOC is primary debulking surgery (PDS) followed by platinum-based chemotherapy. On the other hand, it is generally supported that massive ascites, poor performance status, malnutrition, and pleural effusion are often associated with extensive disease spread, and in those cases, neoadjuvant chemotherapy (NAC) with interval debulking surgery (IDS) could be a good alternative treatment. Previous randomized clinical trials (EORTC, CHROUS, JCOG0602) reported no difference in survival outcomes in stage IIIC/IV ovarian cancer patients who were treated with NAC plus IDS compared with PDS, and the surgically-related morbidity rate (such as haemorrhagic, infective, and thromboembolic adverse events) was higher in PDS (1-3). However, the problem has been often discussed that these trials resulted in low rate of complete/optimal surgery in both PDS and IDS and median operative time in these trials was shorter than other studies (4-6). The SCORPION trial showed relatively higher rates of complete/optimal surgery in PDS and IDS, 91\% and 81\% respectively, possibly due to introduction of scoring peritoneal dissemination by laparoscopic surgery (7). There was no difference in prognosis between PDS and IDS groups, in spite of improvement in surgical outcome. The SCORPION trial showed that PDS also resulted in significantly higher incidence of perioperative complication than IDS. Diagnostic laparoscopic surgery for advanced EOC is gaining popularity because it is minimally invasive and can achieve the purpose of tumour biopsy as well as evaluate the clinical stage (8). Therefore, ovarian cancer treatment guidelines including those of the National Comprehensive Cancer Network recommend diagnostic laparoscopy for advanced EOC for proper clinical staging and tumour biopsy, but there were few reports on tumour biopsy using laparoscopy $v s$. laparotomy (9).

We introduced tumour biopsy using laparoscopy for patients with preoperative clinical stage IIIC or higher, because we 
Table I. Comparison of patient characteristics between laparoscopy and laparotomy groups.

\begin{tabular}{|c|c|c|c|c|}
\hline & & $\begin{array}{l}\text { Laparoscopy } \\
\mathrm{n}=23\end{array}$ & $\begin{array}{l}\text { Laparotomy } \\
\quad \mathrm{n}=27\end{array}$ & $p$-Value \\
\hline $\begin{array}{l}\text { Median follow up period (months) } \\
\text { [median (IQR)] }\end{array}$ & & $28.4(15.1,35.1)$ & $25.2(10.4,42.5)$ & 0.42 \\
\hline Age mean [median (IQR)] & & $59(56,69.5)$ & $60(51,66)$ & 0.7 \\
\hline \multirow[t]{3}{*}{ Cancer type } & Ovarian cancer & $6(26 \%)$ & $10(37 \%)$ & \multirow[t]{3}{*}{0.42} \\
\hline & Fallopian tube cancer & $14(61 \%)$ & $16(59 \%)$ & \\
\hline & Primary peritoneal cancer & $3(13 \%)$ & $1(4 \%)$ & \\
\hline Clinical stage & IIIB & $3(13 \%)$ & $3(11 \%)$ & \multirow[t]{3}{*}{0.25} \\
\hline \multirow[t]{2}{*}{ (FIGO2018) } & IIIC & $16(70 \%)$ & $23(85 \%)$ & \\
\hline & IVA & $4(17 \%)$ & $1(4 \%)$ & \\
\hline \multirow[t]{3}{*}{ Histology } & High grade serous carcinoma & $22(96 \%)$ & $22(81 \%)$ & \multirow[t]{3}{*}{0.06} \\
\hline & Endometrioid carcinoma & $1(4 \%)$ & $0(0 \%)$ & \\
\hline & Clear cell carcinoma & $0(0 \%)$ & $5(19 \%)$ & \\
\hline \multirow[t]{4}{*}{ Preoperative blood test } & CA125 (U/ml) [median (IQR)] & $773(414,1,723)$ & $1,391(591,2,784)$ & 0.3 \\
\hline & $\mathrm{Alb}(\mathrm{g} / \mathrm{dl})[$ median $(\mathrm{IQR})]$ & $3.7(3.2,4.2)$ & $3.7(3.3,4.0)$ & 0.81 \\
\hline & WBC $(/ \mu \mathrm{l})$ [median (IQR)] & $6,800(6,000,8450)$ & $7,200(6,350,8,500)$ & 0.44 \\
\hline & CRP (mg/dl) [median (IQR)] & $1.29(0.27,4.24)$ & $2.78(1.06,4.93)$ & 0.32 \\
\hline
\end{tabular}

Alb, Albumin; CA125, cancer antigen 125; CRP, C-reactive protein; FIGO, International Federation of Gynecology and Obstetrics; IQR, interquartile range; SD, standard deviation; WBC, white blood cells.

hope that minimally invasive laparoscopic tumour biopsy would allow early introduction of NAC. In this study, we retrospectively evaluated the usefulness and safety of biopsy performed by laparoscopic surgery $v s$. laparotomy for patients with suspected advanced EOC by the preoperative evaluation.

\section{Patients and Methods}

This retrospective study was conducted in the Jikei University Hospital and received approval from the Jikei University ethical review board [27-079(7964)]. The study included patients who were diagnosed with clinically advanced EOC on a preoperative imaging study (computed tomography and/or magnetic resonance imaging) and those for whom complete or optimal cytoreduction in PDS was predicted to be difficult due to massive peritoneal dissemination. We started to perform tumour biopsy using laparoscopy in January 2016. The exclusion criteria were suspected clear cell carcinoma or mucinous carcinoma on a preoperative evaluation because both are resistant to chemotherapy. Patients who underwent laparoscopy between April 2016 and August 2020 were compared with those who underwent exploratory laparotomy between January 2012 and August 2020 for tumour biopsy and clinical staging. The following parameters were compared between groups: patient characteristics, surgical outcomes, perioperative complications, histological diagnosis accuracy, sampling size, time taken to initiate NAC, and postoperative treatment outcomes.

Continuous variables were analysed using Mann-Whitney $U$-test, whereas categorical variables were analysed using the $\chi^{2}$ test. The progression-free survival (PFS) and overall survival (OS) distributions of the patients were calculated using the Kaplan-Meier method. The significance of the survival distribution in each group was assessed using the log-rank test. $p$-Values less than 0.05 was considered statistically significant. All statistical analyses were performed using EZR version 1.54 (10).
In our Institution, we use a 5-mm flexible scope, as the small diameter allows for the observation of the entire abdominal cavity in the presence or absence of external tumour adhesions. The procedure of tumour biopsy using laparoscopy in our hospital is as follows:

(i) A 4-cm skin incision is made at the midline of the lower abdomen.

(ii) A SMART RETRACTOR ${ }^{\circledR}$ (TOP, Tokyo, Japan) with a flap is introduced into the incision, the abdominal cavity is insufflated, and a 5-mm trocar is inserted through a FREE ACCESS ${ }^{\circledR}$ (TOP).

(iii) First, the entire abdominal cavity is inspected to confirm whether there are any adhesions with the abdominal wall.

(iv) The abdominal cavity, including the epigastric region, flanks, and lower abdomen, is fully inspected. The omentum and small intestine are mobilized carefully, and the root of the mesentery is checked for disseminated lesions. In addition, the liver and stomach are mobilized carefully using forceps, and an extensive check is performed to confirm the presence or absence of diaphragmatic lesions.

(v) Resectable lesions in the adnexa, fallopian tubes, omentum, and peritoneum are excised. The tumour is extirpated through the small incision.

\section{Results}

This study enrolled a total of 50 patients, of whom 23 and 27 underwent tumour biopsy using laparoscopy and exploratory laparotomy, respectively (Table I). The median follow-up period was 28.4 months for the laparoscopy group and 25.2 months for exploratory laparotomy. The median age was 59 years in the laparoscopy group and 60 years in the exploratory laparotomy group. Clinical stage IIIC accounted for the largest number of cases (laparoscopy: 70\%; laparotomy: $85 \%$ ). 
Table II. Comparison of surgical outcome between laparoscopy and laparotomy groups.

\begin{tabular}{|c|c|c|c|c|}
\hline & & $\begin{array}{c}\text { Laparoscopy } \\
\mathrm{n}=23\end{array}$ & $\begin{array}{l}\text { Laparotomy } \\
\quad \mathrm{n}=27\end{array}$ & $p$-Value \\
\hline Operative time (minutes) [median (IQR)] & & $85(73,105)$ & $109(85,146)$ & 0.07 \\
\hline Operative blood loss (ml) [median (IQR)] & & $5(5,8)$ & $320(70,580)$ & $<0.001$ \\
\hline Perioperative Complication & & $1(4 \%)^{*} 1$ & $1(4 \%) * 2$ & 1 \\
\hline \multirow[t]{5}{*}{ Site of tumor biopsy } & $\begin{array}{l}\text { Salpingo-oophorectomy } \\
\text { 土omentum or peritonea }\end{array}$ & $8(35 \%)$ & $16(59 \%)$ & 0.052 \\
\hline & $\begin{array}{l}\text { Salpingectomy } \\
\pm \text { omentum or peritonea }\end{array}$ & $8(35 \%)$ & $2(7.5 \%)$ & \\
\hline & Omentum \pm peritonea & $6(26 \%)$ & $4(15 \%)$ & \\
\hline & Peritonea & $1(4 \%)$ & $3(11 \%)$ & \\
\hline & Others & $0(0 \%)$ & $2(7.5 \%)$ & \\
\hline \multirow[t]{3}{*}{ Blood test (POD1) } & Alb (g/dl) [median (IQR)] & $2.9(2.2,3.2)$ & $2.1(1.9,2.5)$ & $<0.05$ \\
\hline & WBC $(/ \mu \mathrm{l})[$ median $(\mathrm{IQR})]$ & $8,600(6,900,10,100)$ & $10,000(8,200,12,000)$ & $<0.05$ \\
\hline & $\mathrm{CRP}(\mathrm{mg} / \mathrm{dl})$ [median (IQR)] & $1.6(0.8,3.3)$ & $7.7(6.5,10.2)$ & $<0.05$ \\
\hline
\end{tabular}

Alb, Albumin; CRP, C-reactive protein; POD, postoperative day; WBC, white blood cells; *1, liver damage; *2, ileus.

Among the final pathological diagnosis, high-grade serous carcinoma accounted for the largest number of cases (laparoscopy: 96\%; laparotomy: $81 \%$ ). Table II shows the surgical outcomes of the two groups. The operative time showed no significant intergroup difference [laparoscopy: 85 (73-105) min vs. laparotomy: 109 (85-146) min (median $(\mathrm{IQR})), p=0.07]$. However, the operative blood loss was significantly less in patients who underwent laparoscopy [laparoscopy: 5 (5-8) ml vs. laparotomy: 109 (85-146) $\mathrm{ml}$ (median (IQR), $p<0.001]$. The laboratory results including white blood cells, C-reactive protein (CRP), and albumin on postoperative day 1 were better in the laparoscopy group than in the laparotomy group. Perioperative complications not requiring treatment occurred in one case in each group. Twenty-one patients who underwent laparoscopy were diagnosed with high-grade serous carcinoma; one had highgrade adenocarcinoma and one had endometrioid carcinoma. Similarly, 21 patients who underwent laparotomy were diagnosed with high-grade serous carcinoma $v s$. six with clear cell carcinoma. The concordance rate of the pathological diagnosis between laparoscopy and IDS was 96\%. The concordance rate for laparotomy was also $96 \%$.

The pathologist suspected high-grade serous carcinoma or endometrioid carcinoma in the patient who was lacking a definite diagnosis. For seven cases in the laparoscopy group and nine cases in the laparotomy group, only the peritoneum and omentum were biopsied and the primary lesion was not removed. In these cases, the median (IQR) surface area of the slide sections at the time of specimen preparation was $266(127-749) \mathrm{mm}^{2}$ in the laparoscopy group and 875 (196$1,820) \mathrm{mm}^{2}$ in the laparotomy group, respectively. There was no significant intergroup difference in the slide surface area. The time it took to confirm the diagnosis was significantly shorter in the laparoscopy group than in the laparotomy group [laparoscopy: 5.0 (3.5-6.5) vs. laparotomy: 6.5 (5.0$9.0)$ days (median $(\mathrm{IQR})), p<0.05)$. The duration from the operation to initiation of NAC was significantly shorter in the laparoscopy group than the laparotomy group [laparoscopy: 12 (7.5-17.5) vs. laparotomy: 16 (11.5-29.5) days (median (IQR)), $p<0.05]$. In the NAC regimen of the laparoscopy group, 15 patients were treated for NAC with dose-dense paclitaxel plus carboplatin (ddTC), 4 with paclitaxel plus carboplatin (TC), and 4 with TC plus an investigational new drug. On the other hand, in the NAC regimen of the laparotomy group, 19 patients were treated with dose dense ddTC, 6 with conventional TC, and 2 with TC plus an investigational new drug. Twenty-two patients (96\%) had IDS in the laparoscopy group vs. $21(76 \%)$ in the laparotomy group $(p=0.16)$. One patient treated with laparoscopy responded well to chemotherapy, but she and her family wished to use chemotherapy alone because of her age (78 years) and low performance status. Six patients treated with laparotomy did not undergo IDS: 2 were elderly (84 years and 85 years), 1 died of adverse events during NAC, and 2 had disease progression. Regarding IDS outcomes, there was no difference in operative time and blood loss [laparoscopy: 380 (328-508) vs. laparotomy: 403 (290-472) $\mathrm{min}, p=0.91$; laparoscopy: 795 (692-1,390) vs. laparotomy: $780(660-1,020) \mathrm{ml}, p=0.82$, respectively]. Eighteen patients $(82 \%)$ underwent complete surgery (no residual tumour) with IDS in the laparoscopy group vs. 16 patients $(76 \%)$ in the laparotomy group (Table III). Figure 1 shows the median PFS and OS after IDS. There was no significant intergroup difference between two groups (PFS: 14.1 for laparoscopy $v s .14 .5$ months for laparotomy, $p=0.63$, OS: 25.4 for laparoscopy vs. 24.7 months for laparotomy, $p=0.53)$. There was no recurrence at the port site in the laparoscopy group during the follow-up period. 
Table III. Comparison of laparoscopy and laparotomy histology and treatment outcomes by group.

\begin{tabular}{|c|c|c|c|c|}
\hline & & $\begin{array}{l}\text { Laparoscopy } \\
\mathrm{n}=23\end{array}$ & $\begin{array}{l}\text { Laparotomy } \\
\quad \mathrm{n}=27\end{array}$ & $p$-Value \\
\hline \multirow[t]{4}{*}{ Histology of biopsy } & High grade serous carcinoma & $21(92 \%)$ & $21(78 \%)$ & \multirow[t]{4}{*}{0.052} \\
\hline & High grade adenocarcinoma & $1(4 \%)$ & $0(0 \%)$ & \\
\hline & Clear cell carcinoma & $0(0 \%)$ & $6(22 \%)$ & \\
\hline & Endometrioid carcinoma & $1(4 \%)$ & $0(0 \%)$ & \\
\hline $\begin{array}{l}\text { Concordance rate for histological diagnosis } \\
\text { between biopsy and IDS }\end{array}$ & & $96 \%$ ( 22 cases) & $96 \%$ ( 26 cases) & 1 \\
\hline $\begin{array}{l}\text { Period from biopsy to start NAC (days) } \\
\text { [median(IQR)] }\end{array}$ & & $12(7.5,17.5)$ & $16(11.5,29.5)$ & $<0.05$ \\
\hline \multirow[t]{3}{*}{ NAC regimen } & ddTC & $15(65 \%)$ & $18(69 \%)$ & \multirow[t]{3}{*}{0.09} \\
\hline & $\mathrm{TC}$ & $4(17.5 \%)$ & $6(23 \%)$ & \\
\hline & TC+others & $4(17.5 \%)$ & $2(8 \%)$ & \\
\hline Rate of IDS performed & $22(96 \%)$ & $21(75 \%)$ & 0.12 & \\
\hline \multirow[t]{3}{*}{ Residual tumor of IDS } & $0 \mathrm{~cm}$ & $18(82 \%)$ & $16(76 \%)$ & \multirow[t]{3}{*}{0.1} \\
\hline & $0-1 \mathrm{~cm}$ & $0(0 \%)$ & $5(24 \%)$ & \\
\hline & $\geq 1 \mathrm{~cm}$ & $4(18 \%)$ & $0(0 \%)$ & \\
\hline Operative time of IDS (min) $($ mean \pm SD) & & $380(328,508)$ & $403(290,472)$ & 0.78 \\
\hline Operative blood loss of IDS $(\mathrm{ml})($ mean \pm SD $)$ & & $795(693,1,393)$ & $780(660,1,020)$ & 0.82 \\
\hline
\end{tabular}

ddTC, Dose dense paclitaxel and carboplatin; IDS, interval debulking surgery; NAC, neoadjuvant chemotherapy; SO, salpingo-oophorectomy; TC, paclitaxel and carboplatin.

\section{Discussion}

Minimally invasive surgery, including traditional laparoscopy and robotic-assisted surgery, is becoming increasingly common in the surgical management of gynaecologic malignancies. According to a report by Conead et al., a questionnaire survey among the members of the Society of Gynecologic Oncology revealed that during the 3-year period between 2004 and 2007, an increasing number of gynaecologists considered minimally invasive surgery appropriate for treating gynaecological malignancies (11). Lin CJ et al. reported that minimally invasive surgery was generally beneficial because of its shorter hospitalization period, decreased rates of perioperative complications, wound infection, and postoperative pain; and quicker recovery (12). The current study demonstrated that tumour biopsy using laparoscopy for advanced EOC had shorter operative time and significantly less perioperative bleeding than exploratory laparotomy and there were no obvious severe perioperative complications. Indeed, this study demonstrated that laparoscopy had a shorter duration from tumour biopsy to NAC than laparotomy because of the rapid recovery. Advanced-stage EOC in particular should be treated as soon as possible. Since patients often have symptoms that interfere with daily life, such as pleural effusion and ascites, laparoscopy can be useful to introduce early therapeutic intervention and improve quality of life.

It has often been discussed that the risk of port site implantation and tumour rupture are challenging issues in laparoscopy for ovarian cancer (13-16). Although the frequency of port-site implantation is reportedly extremely low $(0.97 \%)(17)$, most of these reports were based on earlystage ovarian cancer data rather than those of patients with advanced EOC. Some strategies have been suggested to prevent port-site implantation, such as a decreased number of ports, port-site excision at the time of debulking surgery, peritoneal closure of the port site, and removal of the trocar under pneumoperitoneum (8). At our Institution, the tumour is extracted through the small midline incision and direct removal through a trocar is avoided. Besides, we used a 5$\mathrm{mm}$ trocar to minimize the peritoneal defects except for the midline wound site. No patients who underwent laparoscopy in this study demonstrated port-site implantation. It can be presumed from the previous report and this study that extracting the tumour through the small midline wound site without pneumoperitoneum and using a 5-mm trocar to reduce the peritoneal defect might prevent port-site metastasis.

In this study, laparoscopy was performed only for the purpose of tumour biopsy in patients in whom complete or optimal cytoreduction in PDS was expected to be difficult based on preoperative imaging findings. It was not performed for the purpose of assessing whether complete or optimal cytoreduction was possible or not. Therefore, it may be of concern that laparoscopy would have a negative impact on the prognosis. However, there was no significant difference in prognosis between laparoscopy and laparotomy groups that underwent IDS in our study. Therefore, 
A

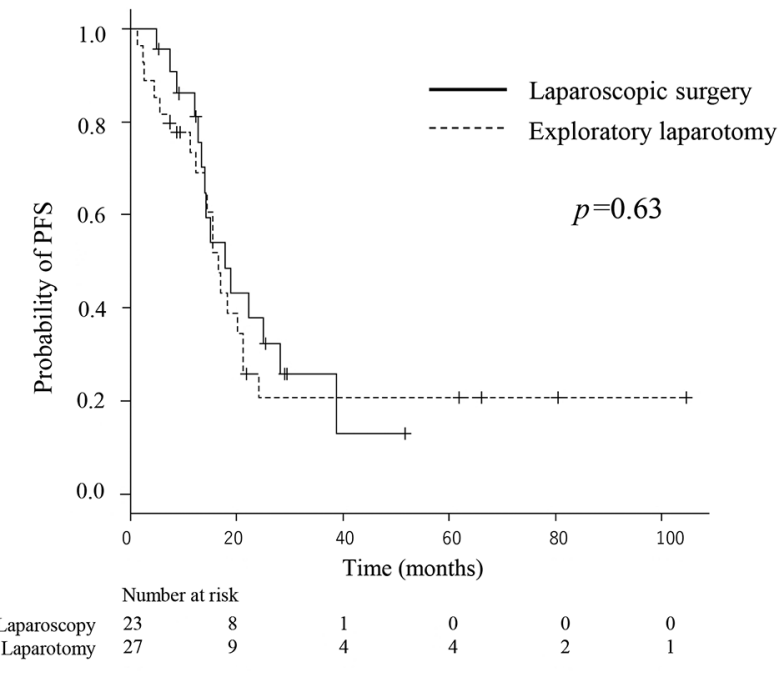

B

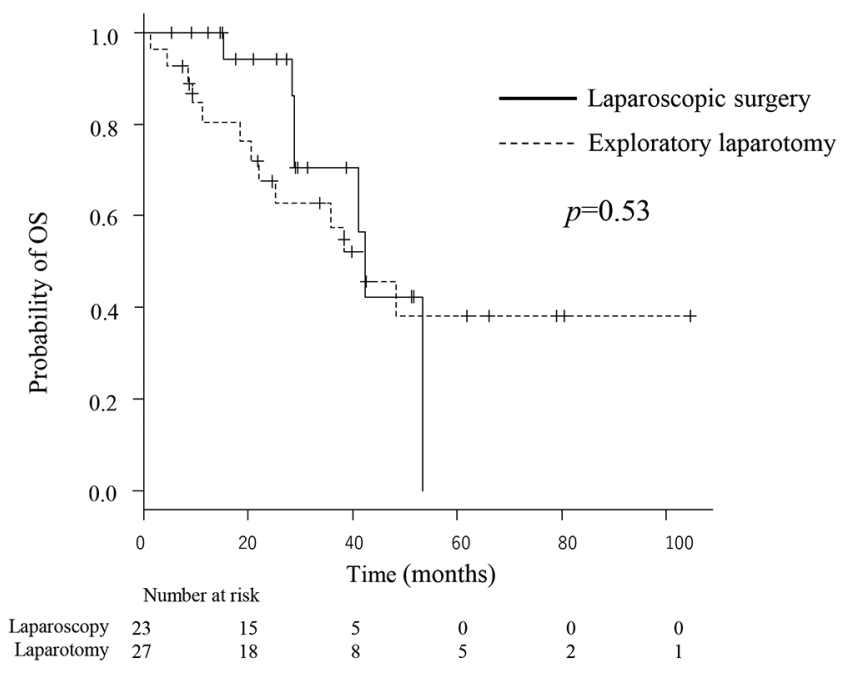

Figure 1. Kaplan-Meier plots of (A) progression-free survival (PFS) and (B) overall survival (OS) for each group that performed IDS.

laparoscopic biopsy is considered to be a non-inferior method to laparotomy biopsy for NAC patients. Moreover Lin CJ et al. stated that minimally invasive surgery in ovarian cancer could reduce the risk of postoperative adhesions, leading to avoidance of surgical complications in IDS (12). In terms of the rates of complete surgery (no residual tumour) and optimal surgery (residual tumour $<1$ $\mathrm{cm}$ ) among patients who underwent IDS, the laparoscopy group had 18 cases $(82 \%)$, while the laparotomy group had 21 cases $(100 \%)(p=0.12)$. Previous clinical trials resulted that the complete/optimal surgery rate was $54-70 \%$ in IDS (1-3). Although our cases were small in number, the rate of complete/optimal surgery in our study was not inferior to previous clinical results. Moreover, the recent clinical study showed that laparoscopy surgery has been introduced as a safely and effectively alternative to laparotomy for staging surgery and IDS (18-20). Tumour biopsy using laparoscopy seemed not to affect the IDS surgery outcome and this method is considered acceptable for advanced EOC.

All patients in both groups had at least a pathological diagnosis of adenocarcinoma from the biopsy specimens. There was no significant difference in either group in the concordance rate for histological diagnosis between biopsy and IDS specimens. This result indicated that there was no difference in diagnostic accuracy. Recently, tumour sampling has been increasingly becoming important to determine adjuvant therapy. Molecular targeted therapies that respond to the individual characteristics of the tumour, such as cancer gene mutations and biomarkers, have been introduced, leading to improved treatment outcomes $(21,22)$. In patients with homologous recombination deficiency (HRD) positivity or $B R C A 1 / 2$ germline or somatic mutations in particular, poly (ADP-ribose) polymerase (PARP) inhibitor therapy showed a clinically significant prognostic benefit. Now there is one companion diagnostic each to identify patients with advanced EOC with positive HRD or BRCA mutation. The HRD status diagnostic system requires slide-mounted sections of formalin-fixed paraffin-embedded tumour tissues at least $40 \mu \mathrm{m}$ thick (23). Gorodnova et al. recently showed that EOC patients with $B R C A 1 / 2$ germ-line mutation show high sensitivity to platinum-based NAC (24), while Kessous et al. reported that the expression of three homologous recombination genes (BRCA2, TP53, and $F A N C B$ ) was associated with prolonged overall survival in EOC patients receiving NAC with IDS (25). Homologous recombination gene status could be a useful parameter to select patients who are more likely to benefit from platinum-based NAC or novel treatments like PARP inhibitors and could guide the selection of patients for enrolment in future neoadjuvant trials $(24,25)$. Conventionally, advanced EOC has been diagnosed based on cytology of ascites and pleural effusion samples, imaging tests, and blood tests, after which treatment is started. For example, in the CHORUS study, $41 \%$ of patients in the NAC group were diagnosed by cytology and chemotherapy was started based on the cytology findings (2). From here on, genome medicine such as molecular targeted medicine and genome screening tests will be widely used in cancer treatment, and sampling tumour specimens will become more important. In our study, tumour sampling was performed from a variety of sites by laparoscopy and laparotomy. Most patients in our study (70\% of those treated with laparoscopic surgery and $66.5 \%$ of those treated with 
laparotomy) were diagnosed with ovarian or fallopian tube cancer, followed by salpingo-oophorectomy or oophorectomy. In some patients, tumour samples were removed from the peritoneum or omentum; these biopsy sizes varied. Our study showed no statistically significant difference in tumour size by surgical method among patients who underwent peritoneal and omental biopsy. In both treatment groups, the smallest tumour section area of biopsy specimens was $30 \mathrm{~mm}^{2}$ for laparoscopic surgery and 37.5 $\mathrm{mm}^{2}$ for laparotomy surgery. These tumour sizes exceeded the amount of tumour needed for genomic examination This study indicated that laparoscopy is comparative in quality and less invasive compared to laparotomy.

\section{Conclusion}

Tumour biopsy using laparoscopy for advanced EOC, including fallopian tube and primary peritoneal carcinoma, is useful in that NAC can be introduced earlier due to faster recovery, and in that sufficient specimens can be obtained for diagnosis and even genetic examination.

\section{Conflicts of Interest}

The Authors declare no conflicts of interest regarding this study.

\section{Authors' Contributions}

Kazu Ueda designed the study. Suguru Odajima wrote the initial draft of the manuscript. Keisuke Tomita and Sayako Kato collected the data. Suguru Odajima contributed to the data analysis and interpretation and assisted in the preparation of the manuscript. All other Authors have contributed to data collection and interpretation and critically reviewed the manuscript. All Authors approved the final version of the manuscript and agreed to be accountable for all aspects of the work by ensuring that questions related to the accuracy or integrity of any part of the work are appropriately investigated and resolved.

\section{Acknowledgements}

Editage provided help with language, writing assistance, and proofreading services for this article for which the authors express our sincere gratitude.

\section{References}

1 Vergote I, Tropé CG, Amant F, Kristensen GB, Ehlen T, Johnson $\mathrm{N}$, Verheijen RH, van der Burg ME, Lacave AJ, Panici PB, Kenter GG, Casado A, Mendiola C, Coens C, Verleye L, Stuart GC, Pecorelli S, Reed NS, European Organization for Research and Treatment of Cancer-Gynaecological Cancer Group and NCIC Clinical Trials Group: Neoadjuvant chemotherapy or primary surgery in stage IIIC or IV ovarian cancer. N Engl J Med 363(10): 943-953, 2010. PMID: 20818904. DOI: 10.1056/NEJMoa0908806
2 Kehoe S, Hook J, Nankivell M, Jayson GC, Kitchener H, Lopes T, Luesley D, Perren T, Bannoo S, Mascarenhas M, Dobbs S, Essapen S, Twigg J, Herod J, McCluggage G, Parmar M and Swart AM: Primary chemotherapy versus primary surgery for newly diagnosed advanced ovarian cancer (CHORUS): an openlabel, randomised, controlled, non-inferiority trial. Lancet 386(9990): 249-257, 2015. PMID: 26002111. DOI: 10.1016/ S0140-6736(14)62223-6

3 Onda T, Satoh T, Saito T, Kasamatsu T, Nakanishi T, Nakamura K, Wakabayashi M, Takehara K, Saito M, Ushijima K, Kobayashi H, Kawana K, Yokota H, Takano M, Takeshima N, Watanabe Y, Yaegashi N, Konishi I, Kamura T, Yoshikawa H and Japan Clinical Oncology Group: Comparison of treatment invasiveness between upfront debulking surgery versus interval debulking surgery following neoadjuvant chemotherapy for stage III/IV ovarian, tubal, and peritoneal cancers in a phase III randomised trial: Japan Clinical Oncology Group Study JCOG0602. Eur J Cancer 64: 22-31, 2016. PMID: 27323348. DOI: 10.1016/j.ejca.2016.05.017

4 Reuss A, du Bois A, Harter P, Fotopoulou C, Sehouli J, Aletti G, Guyon F, Greggi S, Mosgaard BJ, Reinthaller A, Hilpert F, SchadeBrittinger C, Chi DS and Mahner S: TRUST: Trial of Radical Upfront Surgical Therapy in advanced ovarian cancer (ENGOT ov33/AGO-OVAR OP7). Int J Gynecol Cancer 29(8): 1327-1331, 2019. PMID: 31420412. DOI: 10.1136/ijgc-2019-000682

5 Jiang R, Zhu J, Kim JW, Liu J, Kato K, Kim HS, Zhang Y, Zhang P, Zhu T, Aoki D, Yu A, Chen X, Wang X, Zhu D, Zhang W, Jia H, Shi T, Gao W, Yin S, Feng Y, Xiang L, Okamoto A and Zang R: Study of upfront surgery versus neoadjuvant chemotherapy followed by interval debulking surgery for patients with stage IIIC and IV ovarian cancer, SGOG SUNNY (SOC-2) trial concept. J Gynecol Oncol 31(5): e86, 2020. PMID: 32808504. DOI: 10.3802/jgo.2020.31.e86

6 Gasparri ML, Panici PB and Papadia A: Primary chemotherapy versus primary surgery for ovarian cancer. Lancet 386(10009): 2142-2143, 2015. PMID: 26638961. DOI: 10.1016/S01406736(15)01051-X

7 Fagotti A, Ferrandina G, Vizzielli G, Fanfani F, Gallotta V, Chiantera V, Costantini B, Margariti PA, Gueli Alletti S, Cosentino F, Tortorella L and Scambia G: Phase III randomised clinical trial comparing primary surgery versus neoadjuvant chemotherapy in advanced epithelial ovarian cancer with high tumour load (SCORPION trial): Final analysis of peri-operative outcome. Eur J Cancer 59: 22-33, 2016. PMID: 26998845. DOI: 10.1016/j.ejca.2016.01.017

8 Fagotti A, Perelli F, Pedone L and Scambia G: Current recommendations for minimally invasive surgical staging in ovarian cancer. Curr Treat Options Oncol 17(1): 3, 2016. PMID: 26739150. DOI: 10.1007/s11864-015-0379-8

9 National Comprehensive Cancer Network: NCCN Guidelines. Ovarian cancer including fallopian tube cancer and primary peritoneal cancer. Version 4. 2017. Available at: https://www2.tri-kobe.org/nccn/guideline/gynecological/ english/ovarian.pdf [Last accessed on May 25, 2021]

10 Kanda Y: Investigation of the freely available easy-to-use software 'EZR' for medical statistics. Bone Marrow Transplant 48(3): 452-458, 2013. PMID: 23208313. DOI: 10.1038/bmt. 2012.244

11 Conrad LB, Ramirez PT, Burke W, Naumann RW, Ring KL, Munsell MF and Frumovitz M: Role of minimally invasive 
surgery in gynecologic oncology: An updated survey of members of the society of gynecologic oncology. Int J Gynecol Cancer 25(6): 1121-1127, 2015. PMID: 25860841. DOI: 10.1097/IGC.0000000000000450

$12 \mathrm{Lin} \mathrm{CJ}$ and Chen $\mathrm{HJ}$ : The investigation of laparoscopic instrument movement control and learning effect. Biomed Res Int 2013: 349825, 2013. PMID: 23984348. DOI: 10.1155/ 2013/349825

13 Nezhat FR, Pejovic T, Finger TN and Khalil SS: Role of minimally invasive surgery in ovarian cancer. J Minim Invasive Gynecol 20(6): 754-765, 2013. PMID: 24183269. DOI: 10.1016/ j.jmig.2013.04.027

14 Falcetta FS, Lawrie TA, Medeiros LR, da Rosa MI, Edelweiss MI, Stein AT, Zelmanowicz A, Moraes AB, Zanini RR and Rosa DD: Laparoscopy versus laparotomy for FIGO stage I ovarian cancer. Cochrane Database Syst Rev 10: CD005344, 2016. PMID: 27737492. DOI: 10.1002/14651858.CD005344.pub4

15 Lécuru F, Desfeux P, Camatte S, Bissery A, Blanc B and Querleu D: Impact of initial surgical access on staging and survival of patients with stage I ovarian cancer. Int J Gynecol Cancer 16(1): 87-94, 2006. PMID: 16445616. DOI: 10.1111/ j.1525-1438.2006.00303.x

16 Bogani G, Borghi C, Leone Roberti Maggiore U, Ditto A, Signorelli M, Martinelli F, Chiappa V, Lopez C, Sabatucci I, Scaffa C, Indini A, Ferrero S, Lorusso D and Raspagliesi F: Minimally invasive surgical staging in early-stage ovarian carcinoma: a systematic review and meta-analysis. J Minim Invasive Gynecol 24(4): 552-562, 2017. PMID: 28223182. DOI: 10.1016/j.jmig.2017.02.013

17 Abu-Rustum NR, Rhee EH, Chi DS, Sonoda Y, Gemignani M and Barakat RR: Subcutaneous tumor implantation after laparoscopic procedures in women with malignant disease. Obstet Gynecol 103(3): 480-487, 2004. PMID: 14990410. DOI: 10.1097/01.AOG.0000114974.40512.c9

18 Gueli Alletti S, Petrillo M, Vizzielli G, Bottoni C, Nardelli F, Costantini B, Quagliozzi L, Gallotta V, Scambia G and Fagotti A: Minimally invasive versus standard laparotomic interval debulking surgery in ovarian neoplasm: A single-institution retrospective case-control study. Gynecol Oncol 143(3): 516520, 2016. PMID: 27769526. DOI: 10.1016/j.ygyno.2016.10.017

19 Jochum F, Aubry G, Pellerin M, Billard C, Faller E, Boisrame $\mathrm{T}$, Lecointre L and Akladios C: Relevance of laparoscopic surgery for ovarian cancer in well-selected patients: A propensity-matched comparison with laparotomy. Anticancer Res 41(2): 955-965, 2021. PMID: 33517302. DOI: 10.21873/ anticanres.14849
20 Jochum F, Vermel M, Faller E, Boisrame T, Lecointre L and Akladios C: Three and five-year mortality in ovarian cancer after minimally invasive compared to open surgery: a systematic review and meta-analysis. J Clin Med 9(8): 2507, 2020. PMID: 32759715. DOI: $10.3390 /$ jem 9082507

21 Moore K, Colombo N, Scambia G, Kim BG, Oaknin A, Friedlander M, Lisyanskaya A, Floquet A, Leary A, Sonke GS, Gourley C, Banerjee S, Oza A, González-Martín A, Aghajanian C, Bradley W, Mathews C, Liu J, Lowe ES, Bloomfield R and DiSilvestro P: Maintenance olaparib in patients with newly diagnosed advanced ovarian cancer. N Engl J Med 379(26): 2495-2505, 2018. PMID: 30345884. DOI: 10.1056/ NEJMoa1810858

22 Ray-Coquard I, Pautier P, Pignata S, Pérol D, González-Martín A, Berger R, Fujiwara K, Vergote I, Colombo N, Mäenpää J, Selle F, Sehouli J, Lorusso D, Guerra Alía EM, Reinthaller A, Nagao S, Lefeuvre-Plesse C, Canzler U, Scambia G, Lortholary A, Marmé F, Combe P, de Gregorio N, Rodrigues M, Buderath P, Dubot C, Burges A, You B, Pujade-Lauraine E, Harter P and PAOLA-1 Investigators: Olaparib plus bevacizumab as first-line maintenance in ovarian cancer. N Engl J Med 381(25): 24162428, 2019. PMID: 31851799. DOI: 10.1056/NEJMoa1911361

23 Myriad genetics site myChoise ${ }^{\circledR} \mathrm{CDx}$. Available at: https://myriad.com/products-services/precisionmedicine/mychoice-cdx/ [Last accessed on May 25, 2021]

24 Gorodnova TV, Sokolenko AP, Ivantsov AO, Iyevleva AG, Suspitsin EN, Aleksakhina SN, Yanus GA, Togo AV, Maximov SY and Imyanitov EN: High response rates to neoadjuvant platinum-based therapy in ovarian cancer patients carrying germline BRCA mutation. Cancer Lett 369(2): 363-367, 2015. PMID: 26342406. DOI: 10.1016/j.canlet.2015.08.028

25 Kessous R, Octeau D, Klein K, Tonin PN, Greenwood CMT, Pelmus M, Laskov I, Kogan L, Salvador S, Lau S, Yasmeen A and Gotlieb WH: Distinct homologous recombination gene expression profiles after neoadjuvant chemotherapy associated with clinical outcome in patients with ovarian cancer. Gynecol Oncol 148(3): 553-558, 2018. PMID: 29395310. DOI: 10.1016/ j.ygyno.2018.01.017
Received July 25, 2021

Revised August 27, 2021 Accepted September 9, 2021 